\title{
Compreensões sobre as Licenciaturas em Educação do Campo em Ciências da Natureza: Um olhar para os últimos dez anos de Produções Científicas
}

\section{Understandings on field education degrees in Nature Sciences: A look at the last ten years of scientific production}

\author{
Viviane de Almeida Lima (viviane.lima@uffs.edu.br) \\ (Universidade Federal do Rio Grande do Sul e Universidade Federal da Fronteira Sul) \\ José Vicente Lima Robaina (jose.robaina@ufrgs.br) \\ (Universidade Federal do Rio Grande do Sul)
}

Resumo: As Licenciaturas em Educação do Campo foram pensadas e construídas com o intuito de atender a uma reivindicação dos trabalhadores rurais em que pese uma formação voltada especificamente aos educadores do e no referido contexto. Ante a essa perspectiva, o presente trabalho teve como foco analisar compreensões sobre formação de professores da área de Ciências da Natureza nas Licenciaturas em Educação do Campo, a partir das produções socializadas pela comunidade científica brasileira nos últimos dez anos (2009-2019). A pesquisa de cunho qualitativo, denominada de estado do conhecimento, foi submetida à Análise Textual Discursiva, da qual surgiram duas categorias finais: Desafios para o fortalecimento da formação docente em Educação do Campo em Ciências da Natureza e a Formação da identidade docente nas Licenciaturas em Educação do Campo em Ciências da Natureza. Dentre os resultados, destaca-se que, para a consolidação dessa formação docente, a organização curricular deve partir de uma relação dialógica entre os saberes populares advindos dos sujeitos do campo e os conhecimentos científicos, por meio da inter-relação entre o tempo universidade (TU) e o tempo comunidade (TC). No que diz respeito à formação da identidade docente, emergiu a importância dos processos investigativos que possibilitam discussões sociais e políticas.

Palavras-chave: Licenciaturas; formação docente; educadores do campo.

Abstract: Degrees in Rural Education were thought and built with the aim of meeting a demand from rural workers about training specifically aimed to educators in that context. In view of this perspective, the present work focused on analyzing the understandings about the teachers' formation of Natural Sciences field in degrees in Rural Education, based on the productions socialized by the Brazilian scientific community in the last ten years (2009-2019). The qualitative research, called the state of knowledge, was submitted to Discursive Textual Analysis, from which two final categories emerged: Challenges for the strengthening of teacher education in Rural Education in Natural Sciences and the Formation of teacher identity in degrees in Field Education in Natural Sciences. Among the results, it is highlighted that, for the consolidation of this teacher formation, the curricular organization must start from a dialogical relationship between the popular knowledge coming from the subjects of the field and the scientific knowledge, through the interrelation between university time and 
community time. With regard to the formation of the teaching identity, the importance of investigative processes that enable social and political discussions has emerged.

Keywords: Degrees; teacher training; field educators.

\section{INTRODUÇÃO}

Os cursos de Licenciatura em Educação do Campo (LEdoC) surgem da decorrência de discussões nacionais e das lutas dos movimentos sociais para inserção de uma política pública de acesso e permanência no ensino superior, para os sujeitos que moram e vivem no/do campo.

Essa formação de docentes para o campo, no Brasil completa 13 anos, trazendo grandes desafios para as instituições de ensino superior (IES) e novos pressupostos para a organização curricular. Entre elas, pode-se citar a formação por área de conhecimento, que se propõe a formar docentes para os anos finais do Ensino Fundamental e para o Ensino Médio por meio de uma perspectiva interdisciplinar, que leve em consideração os saberes e vivências da população do campo (CALDART, 2011).

Ademais, para as IES, essa perspectiva de formação docente no/do campo significa cumprir com o seu papel inclusivo e democrático, acolhendo os sujeitos do campo com seus modos de pensar e estar no mundo. Isso, de modo a possibilitar a produção de novos conhecimentos num "ambiente historicamente comprometido com a produção e a socialização de saberes" (ANTUNES-ROCHA; DINIZ; OLIVEIRA, 2011).

Em vista disso, as LEdoC levam a pensar num educador no/do campo que esteja comprometido com um projeto educativo que respeite as diversidades sociais, econômicas, culturais e, principalmente, que atente para o tempo, os interesses e as peculiaridade da vida dos estudantes do campo (CALDART, 2004).

Percebe-se que a produção de trabalhos científicos em relação à temática Educação do Campo e Ciências da Natureza são incipientes. Verifica-se uma lacuna ainda maior quando se investiga sobre a formação docente do campo da área de Ciências da Natureza.

Os estudos de Silva et al. (2019) analisaram quatro periódicos nacionais de Educação do Campo procurando compreender como o Ensino de Ciências se insere e é abordado nas Licenciaturas em Educação do Campo. Esse mostra, que apenas dois 
artigos versavam sobre o Ensino de Ciências, apontando a necessidade de estudos e pesquisas do Ensino de Ciências na Educação do Campo. O referido trabalho também revelou a necessidade de aprofundamento das discussões dos referenciais que abordam a Educação do Campo e o Ensino de Ciências.

O estudo de Lima e Robaina (2019) investigou a produção dos pesquisadores da área do Ensino de Ciências em relação à formação de professores de Ciências no/do campo presente nas atas do Encontro Nacional de Pesquisa em Educação em Ciências (ENPEC), entre 2009 a 2017. O referido trabalho mostrou que há pouquíssimas produções acadêmicas sobre a docência em Ciências da Natureza na Educação do Campo no ENPEC. Desse modo, sinalizou a necessidade de um aprofundamento do estudo do processo formativo das LEdoC da área de Ciências da Natureza, principalmente no que tange à perspectiva da interdisciplinaridade nesses cursos.

Com base no exposto e decorrente das lacunas apresentadas, intentou-se com o presente trabalho trazer à tona contribuições e reflexões acerca das questões que circundam a formação de professores da área de Ciências da Natureza nas LEdoC. Delineamento tão necessário e fundamental para população que vive e mora no/do campo.

Desta maneira, o presente artigo tem como objetivo analisar as compreensões que emergiram sobre formação de professores da área de Ciências da Natureza nas LEdoC, a partir das produções socializadas pela comunidade científica brasileira nos últimos dez anos (2009-2019).

Para dar conta dos resultados perscrutados, organizou-se este trabalho em cinco sessões principais. Esta primeira, contextualiza o assunto, expondo e justificando sua problemática, bem como os objetivos do estudo. Na sequência, teoriza-se, brevemente, a Educação do Campo e a formação de professores da área de Ciências da Natureza a importância de interligação desses dois campos de conhecimento. Na seção seguinte apresenta-se os procedimentos metodológicos adotados na construção desta pesquisa, partindo-se da coleta e indo-se aos métodos de análise das informações. Em continuidade, apresenta-se e discute-se as categorias que emergiram da análise e que trouxeram compreensões em relação à formação docente do campo da área de Ciências 
da Natureza. Na última seção, apresenta-se as reflexões que permitiram respostas, novas perguntas e o atingimento do objetivo proposto.

\section{EDUCAÇÃO DO CAMPO E A FORMAÇÃO DE PROFESSORES DE CIÊNCIAS DA NATUREZA}

As LEdoC foram pensadas e construídas com o intuito de atender a uma reivindicação dos trabalhadores rurais para que fosse oferecido uma formação específica para os educadores no/do campo. A origem da matriz formativa dessa Licenciatura diz respeito às experiências formativas acumuladas pelos "trabalhadores rurais, especialmente pelo Movimento dos Trabalhadores Rurais Sem Terra (MST), nas lutas pelo direito à terra e à educação, que possibilitaram o acúmulo de forças que levou à elaboração e implantação dos cursos" (MOLINA, 2017, p. 589).

Uma das estratégias propostas para qualificar o processo formativo das LEdoC foi sua oferta por área do conhecimento. Essa organização propicia a articulação dos componentes tradicionalmente disciplinares para uma "abordagem ampliada de conhecimentos científicos que dialogam entre si a partir de recortes da realidade complementares" (MOLINA; SÁ, 2011, p. 48).

E nessa direção pretende-se neste texto tratar especificamente das LEdoC da área de Ciências da Natureza, que articulam conhecimentos da Biologia, da Física e da Química. Essas buscam formar professores que sejam capazes de analisar, para além dos fenômenos de cunho científico e tecnológico, aqueles relacionados ao campo, aos sujeitos que dele fazem parte e a esse contexto peculiar como um todo.

Assim, tais educadores precisam formar-se e atuar numa perspectiva interdisciplinar, relacionando o trabalho docente "à diversidade do campo em todos os seus aspectos: sociais, culturais, políticos, econômicos, de gênero, geração e etnia ANTUNES-ROCHA; DINIZ; OLIVEIRA, 2011, p. 43).

A formação docente pela perspectiva da interdisciplinaridade exige uma postura política do docente, no sentido de assumir as dificuldades que o conhecimento compartimentalizado coloca-se, para assim enxergar além do seu conhecimento específico. Ou seja, necessita do docente uma atitude interdisciplinar que se caracteriza em não mais olhar para as estruturas rígidas do currículo (FAZENDA, 2013). 
Ante ao exposto, compreende-se que a formação docente do campo para a área de Ciências da Natureza se apresenta como um processo formativo desafiador, complexo e, muitas vezes, difícil de ser materializado nas IES. Isso, pois a ruptura com as "tradicionais visões fragmentadas do processo de produção do conhecimento, com a disciplinarização da complexa realidade socioeconômica do meio rural na atualidade, é um dos desafios postos à Educação do Campo" (MOLINA; SÁ, 2011, p. 48).

Um dos desafios a serem enfrentados no processo formativo das LEdoC é em relação aos professores formadores. Estes, na sua maioria, são oriundos de uma formação "extremamente fragmentados, com pouco ou quase nenhum diálogo entre as disciplinas de uma mesma área em sua própria formação” (MOLINA, 2014, p. 14). Outro motivo importante é o fato de que muitos desses educadores não apresentam a "mínima experiência e participação [...] em atividades formativas executadas com o protagonismo dos sujeitos camponeses em luta" (MOLINA, 2014, p.18).

Dessa maneira, os cursos de formação de professores da Educação do Campo por área do conhecimento, e fala-se especialmente dos que se atêm à área de Ciências da Natureza precisam suplantar barreiras, superando a fragmentação dos conteúdos e a disciplinaridade. Tais cursos buscam, ou devem buscar

\begin{abstract}
superar a fragmentação tradicional que dá centralidade à forma disciplinar e mudar o modo de produção do conhecimento na Universidade e na escola do campo, tendo em vista a compreensão da totalidade e da complexidade dos processos encontrados na realidade (MOLINA; SÁ, 2011, p. 48).
\end{abstract}

Outro diferencial nas LEdoC que contribui para a materialização da formação docente, além da formação por área do conhecimento e a perspectiva da interdisciplinaridade, é a Pedagogia da Alternância, vertente que pressupõe a intercalação de tempos/espaços entre a universidade/escola (TU) e a comunidade (TC) em um processo contínuo de aprendizagem.

O tempo-universidade é o período designado para as atividades de formação que acontecem na universidade com o intuito de preparar os dos estudantes para o trabalho educativo. Enquanto o tempo-comunidade é o período em que se desenvolve atividades de formação nas comunidades de origem dos estudantes mediada pela universidade e a escola e/ou comunidade. Entende-se que a organização destes espaços/tempos contribua 
para construção, avaliação e organização dos saberes em um contínuo de aprendizagem.

(ANTUNES-ROCHA, M. I.; DINIZ, L. S.; OLIVEIRA, A. M., 2011).

A Pedagogia da Alternância possibilita aos alunos/professores em formação nas LEdoC reconhecer a "intrínseca relação entre o contexto socioeconômico e territorial da questão camponesa e os processos de formação do educador do campo" (MOLINA; SÁ, 2011, p.44), com o intuito de aproximar as necessidades das realidades vividas nas comunidades.

Antunes-Rocha, Diniz e Oliveira (2011) argumentam que o Tempo Comunidade (TC) permite que os discentes desenvolvam atividades de estudo, leitura e escrita, possibilitando a formação do professor-pesquisador. Também, cria "espaços de pesquisa e produção de experiências inovadoras relativas à escola do e no campo" (ANTUNESROCHA; DINIZ; OLIVEIRA, 2011, p. 25).

Ante ao exposto, salienta-se que as LEdoC em Ciências da Natureza envolvem uma formação diferenciada, que deve consubstanciar conhecimentos científicos e tecnológicos em estreita relação com o contexto do campo, a partir da perspectiva da interdisciplinaridade e da Pedagogia da Alternância. Assim sendo, na sequência explana-se o percurso metodológico percorrido para se identificar algumas perspectivas envolvidas nos processos de formação de professores do e no campo que atuarão no referido campo de conhecimento.

\section{O CAMINHO METODOLÓGICO PERCORRIDOS POR ESTA PESQUISA}

O presente estudo caracteriza-se como qualitativo, em função de buscar o estado do conhecimento para trazer à tona as compreensões sobre a formação de professores de Ciências da Natureza do Campo nos cursos de LEdoC. O estado do conhecimento se define como um estudo bibliográfico que busca identificar e compreender "uma certa produção acadêmica em diferentes campos do conhecimento, tentando responder que aspectos e dimensões que vêm sendo destacados e privilegiados” (FERREIRA, 2002, p. 258).

Nesse sentido, desenvolveu-se este estado do conhecimento com a busca em três bases de dados, a saber: 1) Periódicos nacionais, on-line e classificados no Qualis ${ }^{1}$ A1 e

${ }^{1}$ Classificações das revistas consolidadas no Quadriênio 2013-2016. 
A2 da CAPES, disponível na Plataforma Sucupira, na área de Ensino, 2) Revista Brasileira de Educação do Campo (RBEC), e, 3) Biblioteca Digital de Teses e Dissertações (BDTD), nos últimos 10 anos $^{2}$.

$\mathrm{Na}$ base de dados 1 (Plataforma Sucupira da CAPES) buscou-se pelo descritor "educação do campo" no título, resumo e/ou palavras-chave, obtendo-se 39 artigos Qualis A1 e 133 artigos Qualis A2 que tratavam da temática. A partir disso, fez-se a leitura dos resumos selecionando artigos primeiramente que tratassem das LEdoC, obtendo-se oito artigos Qualis A1 e sete Qualis A2.

Por fim, fez-se a leitura na íntegra desses artigos, na busca pelos que tratassem especificamente das LEdoC da área de Ciências da Natureza, obtendo-se quatro artigos relacionados à temática e que fizeram, então, parte da amostra de pesquisa para este estudo (Quadro 1).

Quadro 1: Artigos selecionados para o estudo da Plataforma CAPES com Qualis A1 e A2

\begin{tabular}{|c|l|l|c|}
\hline Qualis & \multicolumn{1}{|c|}{ Título } & \multicolumn{1}{|c|}{ Autores } & Ano \\
\hline A1 & $\begin{array}{l}\text { Educação do Campo: formação em ciências da natureza } \\
\text { e o estudo da realidade }\end{array}$ & $\begin{array}{l}\text { BRITTO, N. S.; SILVA, T. } \\
\text { G. R. }\end{array}$ & 2015 \\
\hline A1 & $\begin{array}{l}\text { Educação Superior do Campo: Desafios para a } \\
\text { consolidação da Licenciatura em Educação do Campo }\end{array}$ & $\begin{array}{l}\text { HAGE, S. A. M.; SILVA, } \\
\text { H. S. A.; BRITO, M. M. B. }\end{array}$ & 2016 \\
\hline A1 & $\begin{array}{l}\text { Complexos temáticos na formação de professores do } \\
\text { campo }\end{array}$ & $\begin{array}{l}\text { CUNHA, M. B. de M.; } \\
\text { SILVA, J. L. de P. B. }\end{array}$ & 2016 \\
\hline A2 & $\begin{array}{l}\text { Ensino de Ciências: Uma discussão na perspectiva da } \\
\text { Educação do Campo }\end{array}$ & $\begin{array}{l}\text { COSTA, L.G.; AIKAWA, } \\
\text { M. S.;CUNHA, S.I. }\end{array}$ & 2014 \\
\hline
\end{tabular}

A RBEC, segunda base de dados, criada em 2016, classificada no momento como sendo de Qualis B1, da área de Ensino, é um periódico científico que traz discussões, primordialmente, sobre a Educação do Campo. Em vista disso, buscou-se artigos pelo descritor "Ciências da Natureza", totalizando inicialmente 29 trabalhos. Posteriormente, fez-se a leitura do resumo desses artigos para identificar os que se relacionassem às LEdoC da área de Ciências da Natureza, obtendo-se uma amostra final de 11 artigos nessa base de dados (Quadro 2).

\footnotetext{
2 A busca nestas bases de dados se concentrou nos últimos 10 anos, ou seja, entre janeiro/2009 e dezembro/2019. A escolha por esse período associa-se ao ano posterior ao lançamento do primeiro edital público que o Ministério da Educação (MEC), através do programa específico de apoio à formação superior em LEdoC (PROCAMPO), lançou às IES públicas para que ofertassem cursos de Educação do Campo.
} 
Quadro 2: Artigos selecionados da Revista Brasileira de Educação do Campo Qualis B1

\begin{tabular}{|c|c|c|}
\hline Título & Autores & Ano \\
\hline $\begin{array}{l}\text { Formadores de professores em Educação do Campo em } \\
\text { Goiás }\end{array}$ & $\begin{array}{l}\text { FALEIRO, W.; FARIAS, } \\
\text { M.N. }\end{array}$ & 2016 \\
\hline $\begin{array}{l}\text { As contribuições da História das Ciências para formação de } \\
\text { educadores do campo }\end{array}$ & $\begin{array}{l}\text { MENDES, M. P. L.; GRILO, } \\
\text { J. S. P. }\end{array}$ & 2017 \\
\hline $\begin{array}{l}\text { Formação de professores de Ciências da Natureza para } \\
\text { escolas do/no campo na UFFS - Campus Erechim: } \\
\text { perspectivas e desafios }\end{array}$ & $\begin{array}{l}\text { PRSYBYCIEM, } \quad \text { M.M.; } \\
\text { SANTOS, A. P.; SARTORI, J. }\end{array}$ & 2017 \\
\hline $\begin{array}{l}\text { Interculturalidade e conhecimento tradicional sobre a Lua } \\
\text { na formação de professores no/do campo }\end{array}$ & $\begin{array}{l}\text { CREPALDE, R. S.; KLEPKA, } \\
\text { V.; PINTO, T. H. O. }\end{array}$ & 2017 \\
\hline $\begin{array}{l}\text { 1os como mediadores do pro } \\
\text { da Natureza e Matemática na }\end{array}$ & $\begin{array}{l}\text { BORGES, M. G.; FARIA, J. } \\
\text { E. S.; BRICK, E. M. }\end{array}$ & 2017 \\
\hline $\begin{array}{l}\text { da Natureza na Educação do Campo: em defesa } \\
\text { abordagem sócio-histórica }\end{array}$ & $\begin{array}{l}\text { MORADILLO, E. } \quad \text { F; } \\
\text { MESSEDER NETO, H.S.; } \\
\text { MASSENA, E. P. }\end{array}$ & 2017 \\
\hline res do & MARQUES, L.O.C. & 2017 \\
\hline $\begin{array}{l}\text { ilidade, a educação ambiental e o curso de } \\
\text { o Campo: é possível essa aproximação? }\end{array}$ & $\begin{array}{l}\text { ARAÚJO, J.P.; ASSIS, M.P.; } \\
\text { COSTA, E. R. }\end{array}$ & 2017 \\
\hline $\begin{array}{l}\text { Ciências da Natureza e materialismo histórico-dialético: } \\
\text { encontros e desencontros na formação de educadores do } \\
\text { campo }\end{array}$ & ROMANINI NETTO, E. & 2018 \\
\hline $\begin{array}{l}\text { Vivências de estágio supervisionado em Ciências da } \\
\text { Natureza em uma escola do campo: reflexão das práticas } \\
\text { pedagógicas na formação inicial de professores da } \\
\text { Educação do Campo }\end{array}$ & $\begin{array}{l}\text { ARAÚJO, A.S.; PORTO, K. } \\
\text { S. }\end{array}$ & 2019 \\
\hline $\begin{array}{l}\text { Interdisciplinaridade na formação de professores em uma } \\
\text { LEdoC: desafios de ensinar e aprender }\end{array}$ & $\begin{array}{l}\text { ALVES, M. Z..; FALEIRO, } \\
\text { W. }\end{array}$ & 2019 \\
\hline
\end{tabular}

A BDTD, terceira base de dados deste estudo, foi incluída por apresentar a produção acadêmica da Pós-Graduação stricto sensu das IES do Brasil. Nesse sentido, na busca avançada utilizou-se os descritores "Educação do Campo" e "Ciências da Natureza" em "todos os campos”, no período de 2009 a 2019. Obteve-se, assim, 21 dissertações e cinco teses. A partir da leitura dos resumos na íntegra a amostra compôsse de seis dissertações e uma tese, por tratarem especificamente da LEdoC da área de Ciências da Natureza (Quadro 3).

\section{Quadro 3: Trabalhos selecionados da Biblioteca Digital de Teses e Dissertações}

\begin{tabular}{|l|l|l|c|}
\hline \multicolumn{1}{|c|}{ Título } & \multicolumn{1}{|c|}{ Autores } & \multicolumn{1}{|c|}{ IES } & Ano \\
\hline $\begin{array}{l}\text { Caminhos da interdisciplinaridade: da formação } \\
\text { por área de conhecimento à prática educativa de } \\
\text { egressos da Licenciatura em Educação do Campo } \\
\text { Procampo/IFPA, Campus de Castanhal, PA }\end{array}$ & L. & $\begin{array}{l}\text { Universidade Federal } \\
\text { do Ceará (UFC) }\end{array}$ & 2017 \\
\end{tabular}




\begin{tabular}{|c|c|c|c|}
\hline $\begin{array}{l}\text { Em questão: os processos investigativos na } \\
\text { formação inicial de educadores do campo - Área } \\
\text { de Ciências da Natureza e Matemática }\end{array}$ & $\begin{array}{l}\text { HUDLER, T. G. } \\
\text { R. da S. }\end{array}$ & $\begin{array}{l}\text { Universidade } \\
\text { de Sederal } \\
\text { (UFSC) }\end{array}$ & 2015 \\
\hline $\begin{array}{l}\text { Tudo é rede, conexão e simultaneidade! } \\
\text { Problematizações foucaultianas sobre a } \\
\text { interdisciplinaridade: um campo interdisciplinar de } \\
\text { enunciabilidades disciplinares }\end{array}$ & $\begin{array}{l}\text { MITTMANN, } \\
\text { V. de L. }\end{array}$ & $\begin{array}{l}\text { Universidade Federal } \\
\text { do Rio Grande do Sul } \\
\text { (UFRGS) }\end{array}$ & 2017 \\
\hline $\begin{array}{l}\text { A controvérsia agroecológica em uma abordagem } \\
\text { intercultural de educação científica: A } \\
\text { biodiversidade nos discursos de Licenciandos do } \\
\text { campo }\end{array}$ & SILVA, D. K. & $\begin{array}{lr}\text { Universidade } & \text { Federal } \\
\text { do Triângulo } & \text { Mineiro } \\
\text { (UFTM) } & \end{array}$ & 2017 \\
\hline $\begin{array}{l}\text { Reflexões sobre a formação docente na área de } \\
\text { conhecimento Ciências da Natureza: A } \\
\text { Licenciatura em Educação do Campo - UFSC }\end{array}$ & PAITER, & $\begin{array}{lr}\text { Universidade } & \text { Federal } \\
\text { de Santa } & \text { Catarina } \\
\text { (UFSC) } & \end{array}$ & 2017 \\
\hline $\begin{array}{l}\text { Um olhar sobre a interdisciplinaridade nas em } \\
\text { Educação do Campo, nas Ciências da Natureza, no } \\
\text { Rio Grande do Sul }\end{array}$ & SÁUL, T. S. & $\begin{array}{lr}\text { Universidade } & \text { Federal } \\
\text { de Santa } & \text { Maria } \\
\text { (UFSM) } & \\
\end{array}$ & 2018 \\
\hline $\begin{array}{l}\text { Princípios do Movimento de Educação do Campo: } \\
\text { análise dos Projetos Político-Pedagógicos das } \\
\text { LEdoCs do Centro-Oeste brasileiro }\end{array}$ & FARIAS, M. N. & $\begin{array}{l}\text { Universidade Federal } \\
\text { de Goiás (UFG) }\end{array}$ & 2018 \\
\hline
\end{tabular}

A análise das informações se deu pelo método de Análise Textual Discursiva. Esta consiste em um "processo auto-organizado de construção de novos significados em relação a determinados objetos de estudo, a partir de materiais textuais referentes a esses fenômenos" (MORAES; GALIAZZI, 2011, p. 45).

De acordo com Moraes e Galiazzi (2011), à Análise Textual Discursiva principia com a desconstrução dos textos, formando unidades de significado a partir do corpus de análise. Dessa maneira, fez-se a leitura dos trabalhos selecionados e iniciou-se a unitarização (usou-se fragmentos significativos e representativos para a finalidade da pesquisa, a partir das considerações finais dos materiais), de onde emergiram 87 unidades de significado.

O momento seguinte consistiu no estabelecimento de relações entre as unidades de significado, formando-se as categorias iniciais, intermediárias e finais (MORAES; GALIAZZI, 2011). Nesse processo de categorização obteve-se 11 categorias iniciais, cinco categorias intermediárias e duas categorias finais.

A análise e compreensão dos dados produzidos fez surgir os metatextos, nos quais acontecem o diálogo com autores e teorias que permitem elucidar o objeto de análise (MORAES; GALIAZZI, 2001). Assim, tal construção se deu, conforme segue, de acordo com as duas categoriais finais, a saber: 1) Desafios para o fortalecimento da 
formação docente em Educação do Campo em Ciências da Natureza; e, 2) Formação da identidade docente nas LEdoC em Ciências da Natureza.

\section{O QUE EMERGIU DAS COMPREENSÕES SOBRE A FORMAÇÃO DE PROFESSORES DO CAMPO DA ÁREA DE CIÊNCIAS DA NATUREZA}

Nos Quadros 1, 2 e 3 estão listados os trabalhos que compuseram a análise nas três diferentes bases de dados. A partir desses percebeu-se que os trabalhos sobre a temática formação de professores da área de Ciências da Natureza nas LEdoC principia em 2014 com um trabalho, mas se intensifica no ano de 2017, onde figuram 11 trabalhos. Isso revela um crescimento de pesquisas, ainda que pequeno, sobre a compreensão do processo formativo dos cursos de Educação do Campo, especificamente da área de Ciências da Natureza, nestas bases de dados.

Por meio dos dados apresentados no Gráfico 1, pode-se observar a relação existente entre publicações que versam sobre a Educação do Campo e as que tratam especificamente sobre a formação docente da área de Ciências da Natureza nas LEdoC, nas três bases de dados. Verifica-se que a RBEC apresentou um número significativo de trabalhos relacionados à formação docente da área de Ciências da Natureza, enquanto nas revistas Qualis A1 e A2 o número é muito pequeno. (acrescentar q trata-se de uma revista específica.

Dessa maneira, fica claro o quanto se precisa avançar nas pesquisas sobre os cursos de Licenciatura em Educação do da área de Ciências da Natureza, pois pensando no quantitativo de cursos existentes no Brasil (42 cursos), considera-se que haja trabalhos sendo realizados e que necessitam ser publicizados para a comunidade científica. 


\section{Trabalhos sobre a formação docente eI Ciências da Natureza publicados nas bas de dados}

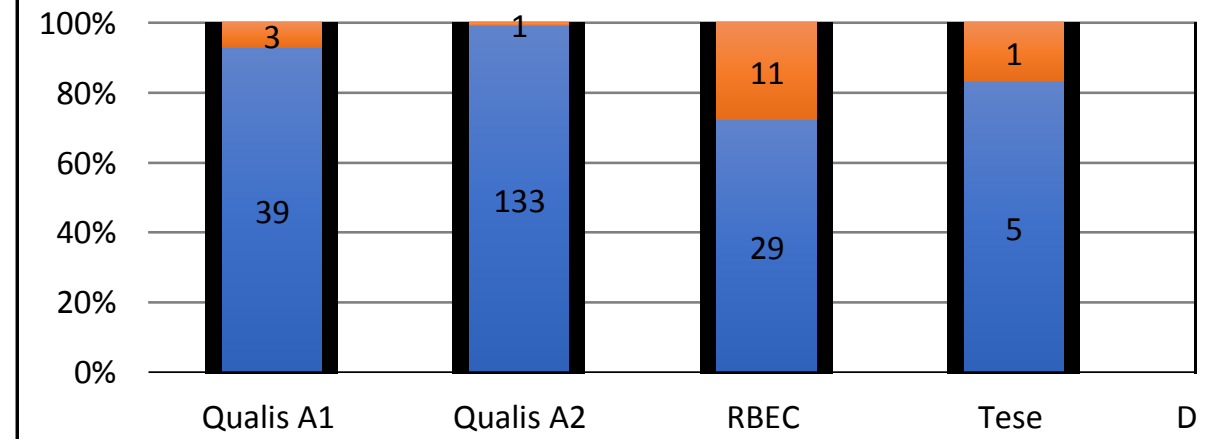

Gráfico 1. Artigos sobre a formação docente em Educação do Campo em Ciências da Natureza

Ante a tais constatações, pretende-se de agora em diante, seguindo-se as categorias finais de análise, apresentar as considerações que emergiram dos textos, trazendo-se compreensões sobre a formação de professores da área de Ciências da Natureza das LEdoC. Isso, a partir do que a comunidade científica tem discutido e problematizado nestes últimos 10 anos (2009-2019) e socializado nas bases de dados consideradas.

4.1. Desafios para o fortalecimento da formação docente em Educação do Campo em Ciências da Natureza

Nesta categoria emergiram compreensões em relação ao desafio para a fortalecimento da formação docente em Educação área de Ciências da Natureza nas Licenciaturas em Educação do Campo. Dentre elas, destacou-se a organização curricular por área do conhecimento, o trabalho interdisciplinar e a Pedagogia da Alternância como facilitadores da relação dialógica entre os saberes populares e os conhecimentos científicos.

As LEdoC desencadearam nas IES não só uma reorganização no processo formativo docente, bem como reflexões, estudos e pesquisas de como "contribuir com a produção de conhecimento, materialização e valorização crítica da cultura do campo" (BRICK et al., 2014, p. 43). Ainda, potencializaram o debate de como concretizar e 
fortalecer a relação entre a área de Ciências da Natureza e a Educação do Campo para a emancipação da população que vive e mora nesse contexto.

Diante disso, entende-se que o ensino de Ciências da Natureza nos cursos de Licenciatura em Educação do Campo deve atentar para os diferentes saberes populares entrecruzando com os saberes científicos e com o modo de vida campesina. Para que assim, os saberes do campo estejam integrados aos conteúdos de Ciências da Natureza com a finalidade de capacitar os sujeitos do campo em transformar e potencializar a realidade local.

Compreendeu-se, no percurso analítico deste estudo, que na organização dos currículos das LEdoC ocorreu fortes contribuições dos movimentos sociais, dando visibilidade à construção coletiva do instrumento. Isso tudo, com o intuito de "preservar a radicalidade da proposta [...] alinhado com as intenções emancipatórias" (FARIAS, 2018, p. 200) para, assim, romper "com o formato de universidade positivista, colonialista e mercadológica" (FARIAS, 2018, p. 200). Conforme Molina (2017) a matriz curricular dos cursos LEdoC deveriam estar ligadas as experiências formativas do MST e a luta à educação.

Moradillo, Messeder Neto e Massena (2017, p.106) defendem em seu trabalho que o currículo das LEdoC em Ciências da Natureza deve apresentar como pressuposto a “concepção sócio-histórica de homem, natureza e sua relação, a partir do trabalho, com suas consequências na concepção de sociedade, conhecimento, ciência, educação, ensino e aprendizagem". Isso, para superar a "perspectiva idealista de educação e de ciência empírico-analítica" (MORADILLO, MESSEDER NETO e MASSENA, 2017 p.1016), buscando-se avançar na emancipação humana dos sujeitos do campo na luta contra a hegemonia da sociedade e da educação.

A origem da matriz formativa dessa Licenciatura diz respeito às experiências formativas acumuladas pelos "trabalhadores rurais, especialmente pelo Movimento dos Trabalhadores Rurais Sem Terra (MST), nas lutas pelo direito à terra e à educação, que possibilitaram o acúmulo de forças que levou à elaboração e implantação dos cursos" (MOLINA, 2017, p. 589).

Dessa forma, entende-se que a educação é uma prática social em direção a um projeto de humanidade. Ademais “os docentes [...] são sujeitos responsáveis pela 
socialização desses conhecimentos sistematizados para as gerações futuras" (ANUNCIAÇÃO; MESSEDER NETO; MORADILLO, 2015, p.250). Em complemento, compreendem os referidos autores que

as contradições possíveis de serem superadas via processo educativo são aquelas provenientes do trato com o conhecimento e seus desdobramentos na ação. Podemos e devemos a partir do ato educativo dominar os conhecimentos socialmente relevantes, resgatar a consciência de classe, desenvolver a formação política e atuar socialmente através das organizações sociais existentes (partidos políticos, sindicatos, etc.), na busca de emancipação humana (ANUNCIAÇÃO; MESSEDER NETO; MORADILLO, 2015, Op. cit., p.250).

Com o propósito de garantir o acesso e a permanência desses sujeitos nas LEdoC é que se organizou os currículos permeados pelas ideias da Pedagogia da Alternância e da formação por área de conhecimento pela perspectiva da interdisciplinaridade.

Tais direcionamento visavam a "concretização de uma educação emancipatória coerente com o projeto de nação almejado pela Educação do Campo" (BRITTO; SILVA, 2015, p. 763).

Em sentido convergente, entendeu-se que na organização do currículo do ensino de Ciências da Natureza, levando-se em conta os pressupostos da Pedagogia da Alternância, deve-se tomar em consideração a necessidade da inserção do conhecimento "a partir de estratégias que demarquem as fronteiras e os contextos de uso entre o tradicional e o científico e que [...] estimule o intercâmbio e o enriquecimento mútuo" (CREPALDE; KLEPKA; PINTO, 2017, p. 857).

Do mesmo modo, compreendeu-se que é na relação dialógica entre os saberes populares e os conhecimentos científicos e tecnológicos que se pode "instrumentalizar os povos do campo para a luta por igualdade e por justiça social (PRSYBYCIEM; SANTOS; SARTORI, 2017, p. 961).

Para a consolidação das LEdoCs destacaram-se nos textos analisados a Pedagogia da Alternância

como estratégia teórico-metodológica que oportuniza o diálogo entre teoria e prática e que motiva os estudantes a investigarem e a intervirem nos problemas enfrentados pelos sujeitos do campo no trabalho, nas escolas de educação básica e nos demais espaços (HAGE; SILVA; BRITO, 2016, p.171). 
Como descrito por Prsybyciem, Santos e Sartori (2017), a Pedagogia da Alternância pode potencializar a aproximação dos componentes curriculares dos cursos e esses com a realidade dos sujeitos envolvidos. Assim, essa vertente pedagógica pode "aproximar todos os componentes curriculares [...], a realidade das comunidades, da escola e dos seus sujeitos” (PRSYBYCIEM, SANTOS e SARTORI, 2017, p. 960).

Tal encadeamento pode identificar temas que se articulem com as Ciências da Natureza, "permitindo compreender as contradições e os problemas complexos de ordem ambiental, social, tecnológica, científica, econômica, política, ética e ideológica" (PRSYBYCIEM, SANTOS e SARTORI, 2017, p. 960).

Em Silva (2017b) encontra-se também referência ao potencial da Pedagogia da Alternância para o contexto em pauta. O autor afirma que o TC e o TU necessitam, para efetivarem-se, da ocorrência da interdisciplinaridade, pois, somente assim, os discentes conseguem estabelecer relações com as disciplinas e com a pesquisa na comunidade.

Para o autor, a interdisciplinaridade "amplia a visão das inter-relações de disciplinas, da relação dialógica [...] ao olhar um objeto em suas diversas possibilidades do conhecimento, para se poder explicar a totalidade dos fenômenos natural e social" (SILVA, 2017b, p. 210-211).

Nesse sentido, a interdisciplinaridade é relevante no processo formativo das LEdoCs em Ciências da Natureza. Visto que é uma possibilidade de "entender a estrutura do currículo e de organizar os conhecimentos construídos historicamente, os quais sejam realmente necessários para a relação do homem com o mundo" (SÁUL, 2018, p.120).

Dessa maneira, a interdisciplinaridade passa a ser compreendida como uma forma de apreender a organização curricular e os conhecimentos historicamente construídos, muito mais do que uma simples metodologia a ser defendida (SÁUL, 2018).

Em síntese, para compreender os desafios para o fortalecimento da formação docente em Ciências da Natureza nas LEdoCs, torna-se imprescindível que a organização curricular seja por área do conhecimento pela perspectiva da formação interdisciplinar e ancorada na Pedagogia da Alternância. 


\subsection{Formação da identidade docente nas Licenciaturas em Educação do Campo da área de Ciências da Natureza}

Nesta categoria emergem compreensões de que a formação da identidade docente perpassa pelas práticas pedagógicas que valorizam os diferentes conhecimentos dos sujeitos do campo. Ainda, de que prescinde de uma formação permanente dos docentes formadores, por meio da participação em espaços diversos para isso e de planejamento coletivo nas LEdoC.

Dessa maneira, a identidade dos docentes das LEdoC se constitui por meio do contexto sócio-histórico da Educação do Campo. Ou seja, pela "luta do povo do campo por políticas públicas que garantam o seu direito à educação e a uma educação que seja no e do campo" (CALDART, 2011, p. 149, grifo nosso). Para a referida autora, no campo significa educar os sujeitos no lugar onde vivem e o do campo significa uma educação pensada do lugar e com a participação dos sujeitos e suas especificidades.

Entende-se, assim, que a formação da identidade docente para a Educação do Campo necessita compreender a realidade da comunidade e, dessa maneira, fazer com que as práticas pedagógicas perpassem pelas questões sociais, relacionando conteúdos científicos escolares com os reais (CUNHA; SILVA, 2016). Some-se a isso, que a formação da identidade docente deve abarcar que o ensino de Ciências é possibilitador de uma "ação educativa destinada à formação humana [...] através do conhecimento científico contextualizado e articulado com as necessidades do campo" (COSTA; AIKAWA; CUNHA, 2014, p.168).

Do ponto de vista de Mendes e Grilo (2017), a formação da identidade docente deve ser construída, também, a partir de uma prática pedagógica diferenciada. Em que seja possível produzir "o conhecimento de forma compartilhada com os alunos, por meio de debates, pesquisas e com autonomia do pensamento, distanciando-se do ensino tradicional propedêutico e acrítico" (Mendes e Grilo2017, p.647).

Quando se refere a formação da identidade docente nos cursos de Licenciatura em Educação do Campo, Molina e Sá (2011) apresentam como desafio o processo formativo disciplinar e fragmentado que ainda é majoritariamente praticado nas IES. 
Dessa forma, representa um grande desafio epistemológico a incorporação de uma outra concepção de ciência e formação, que levem em conta a experiência, participação e o protagonismo dos sujeitos envolvidos.

Outra lacuna, apontada por Sául (2018), refere-se à inadequada formação inicial de tais professores-formadores, denotando frágeis "espaços coletivos de planejamento, nos quais os educadores poderiam vivenciar o diálogo e o estudo" (Op. cit., p.119). Ademais, este é um dos desafios apontados por Molina (2014) para a efetivação das Licenciaturas em Educação do Campo. Visto que a grande maioria dos professoresformadores são provenientes de uma formação fragmentada, específica e sem o mínimo contato em seu processo formativo com os sujeitos camponeses.

Entretanto, Faleiro e Farias (2016), ao avaliarem os percursos acadêmicos dos formadores de professores da LEdoC no estado de Goiás, afirmam que mesmo com a formação disciplinar, tais profissionais voltam seus olhares para a Educação do Campo da área de Ciências da Natureza. Ainda, se dedicam não só para o ensino, mas também para pesquisas e extensão para a temática. Também, para os referidos autores,

As licenciaturas em Educação do Campo precisam intensificar e incentivar o diálogo e a coletividade entre docentes, pois a formação docente é complexa e requer interações entre conhecimentos e saberes de forma participativa com as comunidades rurais, e quanto antes essas relações forem efetivadas no seio de cada IES, melhor será a consolidação e a formação identitária dessa nova licenciatura (Op. cit., p.105, grifo nosso).

$\mathrm{Na}$ mesma direção, Hudler $(2015$, p. 164) refere que o diálogo favorece e possibilita o esclarecimento e discussão na seleção dos conteúdos e que os momentos de "reflexão e discussão dos referenciais teórico-metodológicos [podem ser] efetivamente subsídios para o planejamento dos processos formativos".

Em síntese, há a necessidade da formação permanente e do diálogo constante para a construção da identidade dos docentes-formadores atuantes na Educação do Campo da área de Ciências da Natureza, bem como "espaços coletivos de planejamento, nos quais os educadores poderiam vivenciar o diálogo e o estudo" (SÁUL, 2018, p.119).

\section{CONSIDERAÇÕES FINAIS}

O presente estudo deu-se com o intuito de compreender como tem sido abordado pela comunidade científica a formação de professores da área de Ciências da Natureza 
nos cursos de Educação do Campo, nos últimos dez anos (2009-2019). Para tanto, a partir de três bases de dados (CAPES, RBEC e BDTD) conformou-se uma amostra de 22 publicações submetidas à Análise Textual Discursiva. A referida conduta fez emergir duas categorias finais - Desafios para o fortalecimento da formação docente em Educação do Campo em Ciências da Natureza e a Formação da identidade docente nas LEdoC em Ciências da Natureza - sobre as quais se conclui.

Quando se trata de compreender os desafios para o fortalecimento da formação docente em em Ciências da Natureza nas LEdoCs, percebe-se que essa perpassa pela premência da organização curricular do processo formativo por área do conhecimento numa perspectiva da interdisciplinaridade. Tais perspectivas, preferencialmente, que sejam pensadas, discutidas e protagonizadas a partir das contribuições dos movimentos sociais, no sentido de preservar o projeto "Por uma Educação do Campo" e as intenções de uma educação emancipatória para e com os sujeitos do campo.

Outro ponto importante destacado para a consolidação da formação docente em Educação do Campo em Ciências da Natureza foi a Pedagogia da Alternância. Esta oportuniza o diálogo entre a teoria e prática e proporciona a relação dialógica entre os saberes populares e o conhecimento científico e tecnológico, com o intuito de investigar e intervir nos diferentes espaços vivenciados pelos discentes.

Quando se discute a formação da identidade docente nas Licenciaturas em Educação do Campo em Ciências da Natureza emerge compreensões sobre a prática pedagógica em que leve em consideração a realidade e as necessidades dos sujeitos do campo e relacione com os conteúdos científicos de maneira interdisciplinar, contextualizada e que promova a autonomia do pensamento.

$\mathrm{Na}$ direção da segunda categoria emergida do trabalho de pesquisa e análise, infere-se que a construção da identidade docente na LEdoC perpassa pelos professores/formadores que se caracterizam por formações primárias disciplinares e fragmentadas.

No entanto, percebeu-se que muitos deles voltam seus interesses, estudos e pesquisas para a temática da Educação do Campo e suas interfaces. Entende-se, assim, que o diálogo entre tais docentes e as comunidades rurais onde atuam possibilita as 
interações de conhecimento e saberes, promovendo a formação da identidade dos docentes em Educação do Campo em Ciências da Natureza.

Ante ao exposto e à guisa de conclusão, compreende-se que a partir das experiências de mais de 13 anos de cursos de Educação no Campo no país, pode-se considerar que ocorre uma lacuna na produção científica de trabalhos que tratem especificamente das LEdoC da área de Ciências da Natureza. Assim, defende-se a importância e a manutenção de tais cursos na direção de serem responsáveis e imprescindíveis à articulação dos conhecimentos científicos com os saberes da comunidade.

Desta maneira, entende-se que a materialização da formação do docente no e do campo é complexa. Ademais, é um grande desafio para todos os envolvidos no processo formativo, exigindo uma maneira diferente de pensar a organização curricular, pedagógica e comunitária nas próprias IES.

\section{REFERÊNCIAS}

ALVES, M. Z.; FALEIRO, W. Interdisciplinaridade na formação de professores em uma LEDOC: desafios de ensinar e aprender. Rev. Bras. Educ. Camp, Tocantinópolis, v. 4, e5368, 2019. DOI: http://dx.doi.org/10.20873/uft.rbec.e5368.

ANTUNES-ROCHA, M. I.; DINIZ, L. S.; OLIVEIRA, A. M. Percurso formativo da Turma Dom José Mauro: segunda turma do curso de Licenciatura em Educação do Campo da FAE-UFMG. In: MOLINA, M. C.; SÁ, L. M. Licenciaturas em educação do campo: registros e reflexões a partir das experiências piloto. Belo Horizonte: Autêntica, 2011. p.19-34.

ANUNCIAÇÃO, B. C. P da; MESSEDER NETO, H. da S.; MORADILlO, E. F. de. A pedagogia histórico crítica na formação de professores de ciências do curso de Licenciatura em Educação do Campo da UFBA. Germinal: Marxismo e Educação em Debate, v.7, n.1, p.243-252, jun. 2015. Disponível em:

https://portalseer.ufba.br/index.php/revistagerminal/article/view/12422/9517. Acesso em: 18 nov. 2019.

ARAÚJO, A. dos S.; PORTO, K. S. Vivências de estágio supervisionado em Ciências da Natureza em uma escola do campo: reflexão das práticas pedagógicas na formação inicial de professores da Educação do Campo. Revista Brasileira de Educação do Campo, v. 4, p.e 4132, 28 jan. 2019. DOI: https://doi.org/10.20873/uft.rbec.v4e4132.

ARAÚJO, J. P.; ASSIS, M. P.; COSTA, E. R. A sustentabilidade, a educação ambiental e o curso de Educação do Campo: é possível essa aproximação?. Revista Brasileira de 
Educação do Campo, v. 2, n. 3, p. 921-940, 13 dez. 2017. DOI:

https://doi.org/10.20873/uft.2525-4863.2017v2n3p921.

BORGES, M. G.; FARIA, J. E. S.; BRICK, E. M. Fenômenos como mediadores do processo educativo em Ciências da Natureza e Matemática na Educação do Campo. Revista Brasileira de Educação do Campo, v. 2, n. 3, p. 965-990, 13 dez. 2017. DOI: https://doi.org/10.20873/uft.2525-4863.2017v2n3p965.

BRICK, E.M.; PERNAMBUCO, M.M.C.A.; SILVA, A.F.G.; DELIZOICOV, D. Paulo Freire: interfaces entre ensino de Ciências Naturais e Educação do Campo. In: MOLINA, M. C. (Org.). Licenciaturas em Educação do Campo e o ensino de Ciências Naturais: desafios à promoção do trabalho docente interdisciplinar. Brasília: MDA, 2014. (Série NEAD Debate; 23). p.23-59.

BRITTO, N. S.; SILVA, T. G. R.da. Educação do campo: formação em ciências da natureza e o estudo da realidade. Educ. Real., Porto Alegre, v. 40, n. 3, p. 763-784, set. 2015. Disponível em http://www.scielo.br/scielo.php?script=sci_arttext\&pid=S2175$62362015000300763 \& \operatorname{lng}=$ pt\&nrm=iso. Acesso em: 02 fev. 2020.

CALDART, R. S. Por uma educação do campo: traços de uma identidade em construção. In: ARROYO, M.; CALDART, R. S.; MOLINA, M. (Orgs.). Por uma educação do campo. 5.ed. Petrópolis, RJ: Vozes, 2004. p.147-158.

CALDART, R. S. Licenciaturas em educação do campo e projeto formativo: qual o lugar da docência por área? In: MOLINA, M. C.; SÁ, L. M. Licenciaturas em Educação do campo: Registros e reflexões a partir das experiências piloto. Belo Horizonte: Autêntica, 2011. p.95-121.

COSTA, L.; AIKAWA, M. Ensino de ciências: uma discussão na perspectiva da educação do campo. Revista Areté | Revista Amazônica de Ensino de Ciências, v. 7, n. 13, p. 161-169, 2014. Disponível em:

http://periodicos.uea.edu.br/index.php/arete/article/view/111. Acesso em: 02 fev. 2020. Ver cunha

CREPALDE, R. S.; KLEPKA, V.; PINTO, T. H. O. Interculturalidade e conhecimento tradicional sobre a Lua na formação de professores no/do campo. Rev. Bras. Educ.

Camp., Tocantinópolis, v. 2, n.3, p. 836-860, 2017.

DOI: https://doi.org/10.20873/uft.2525-4863.2017v2n3p836.

CUNHA, M. B. de M.; SILVA, J. L. de P. B. Complexos temáticos na formação de professores do campo. Educ. rev., Curitiba, n. 61, p. 171-188, set. 2016. Disponível em: http://www.scielo.br/scielo.php?script=sci_arttext\&pid=S0104-

40602016000300171\&lng=en\&nrm=iso. Acesso em: 02 fev. 2020.

FALEIRO, W.; FARIAS, M. N. Formadores de professores em educação do campo em Goiás. Revista Brasileira de Educação do Campo, v. 1, n. 1, p. 88-106, jan./jun. 2016. Disponível em:

https://sistemas.uft.edu.br/periodicos/index.php/campo/article/view/2111. Acesso em: 8 mar. 2019. 
FARIAS, M. N. Princípios do movimento de educação do campo: análise dos projetos políticos-pedagógicos da LEdoCs do centro oeste brasileiro. 2018. $216 \mathrm{f}$. Dissertação (Mestrado) - Universidade Federal de Goiás, Catalão, 2018. Disponível em: https://repositorio.bc.ufg.br/tede/handle/tede/9690. Acesso em: 12 fev. 2019.

FAZENDA, I.C.A. Formação de professores: dimensão interdisciplinar. In: FAZENDA, I.C.A.; FERREIRA, N.R.S. Formação de docentes interdisciplinares. 1 ed. Curitiba, PR: CRV, 2013.

FERREIRA, N. S. A. As pesquisas denominadas "estado da arte". Educação \& Sociedade, ano 23, n. 79, p.257-272, ago. 2002. Disponível em: https://www.scielo.br/pdf/es/v23n79/10857.pdf. Acesso em: 2 mar. 2019.

HAGE, S. A. M.; SILVA, H. do S. de A.; BRITO, M. M. B.. Educação superior do campo: desafios para a consolidação da licenciatura em educação do campo. Educ. rev., Belo Horizonte, v. 32, n. 4, p. 147-174, dez. 2016. Disponível em: $<$ http://www.scielo.br/scielo.php?script=sci_arttext\&pid=S010246982016000400147\&lng=en\&nrm=iso $>$. Acesso em: 02 fev. 2020.

HUDLER, T. G. R. da S. Em questão: os processos investigativos na formação inicial de educadores do campo - área de ciências da natureza e matemática. 2015. Dissertação (Mestrado em Educação Científica e Tecnológica) - Universidade Federal de Santa Catarina, Florianópolis, 2015. Acesso em: 17 fev. 2020.

LIMA, V. de A.; ROBAINA, J. V. L. Formação de professores do campo de ciências da natureza: o que os Encontros Nacionais de Pesquisa em Educação em Ciências (ENPECs) de 2009-2017 dizem? In: ENCONTRO NACIONAL DE PESQUISA EM EDUCAÇÃO EM CIÊNCIAS, 12., 2019, Natal. Anais eletrônicos [...]. Natal, RN: UFRN, 2019. Disponível em: http://abrapecnet.org.br/enpec/xiienpec/anais/trabalhos.htm. Acesso em: 20 dez. 2019.

MARQUES, L. O. C. Interculturalidade na formação de professores do campo: análise de uma experiência. Revista Brasileira de Educação do Campo, v. 2, n. 2, p. 447-471, 29 jul. 2017. DOI: https://doi.org/10.20873/uft.2525-4863.2017v2n2p447.

MENDES, M. P. DE L.; GRILO, J. de S. P. A contribuição da história das ciências para formação de educadores do campo. Revista Brasileira de Educação do Campo, Tocantinópolis, v. 2, n. 2, p. 632-649, jul./dez. 2017. Disponível em: https://sistemas.uft.edu.br/periodicos/index.php/campo/article/view/3630/11593. Acesso em: 8 mar. 2019.

MITTMANN, V. de L. Tudo é rede, conexão e simultaneidade: Problematizações Foucaultianas sobre a interdisciplinaridade: um campo interdisciplinar de enunciabilidades disciplinares. 2017. Dissertação (Mestrado) - Universidade Federal do Rio Grande do Sul, Porto Alegre, 2017. Disponível em: https://lume.ufrgs.br/handle/10183/172124. Acesso em: 12 fev. 2020. 
MOLINA, M. C. (Org.). Licenciaturas em educação do campo e o ensino de ciências naturais: desafios à promoção do trabalho docente interdisciplinar. Brasília: MDA, 2014. (Série NEAD Debate; 23).

MOLINA, M. C. Contribuições das licenciaturas em educação do campo para as políticas de formação de educadores. Educação \& Sociedade, v.38, n.140, p. 587-609, jul./set. 2017. Disponível em: https://www.redalyc.org/articulo.oa?id=87353321005. Acesso em: 8 mar. 2020.

MOLINA, M. C.; SÁ, L. M. A licenciatura em educação do campo da Universidade de Brasília: estratégias político-pedagógicas na formação de educadores do campo. In: MOLINA, M. C.; SÁ, L. M. Licenciaturas em educação do campo: registros e reflexões a partir das experiências piloto. Belo Horizonte: Autêntica, 2011. p.35-61.

MORADILLO, E. F.; MESSEDER NETO, H. S.; MASSENA, E. P. Ciências da natureza na educação do campo: em defesa de uma abordagem sócio-histórica. Rev. Bras. Educ. Camp., Tocantinópolis, v. 2, n. 3, p. 991-1019, 2017. Disponível em: https://sistemas.uft.edu.br/periodicos/index.php/campo/article/view/3839. Acesso em: 8 mar. 2019.

MORAES, R.; GALIAZZI, M. C. Análise textual discursiva. 2.ed.rev. Ijuí: Ed. Unijuí, 2011.

ROMANINI NETTO, E. Ciências da natureza e materialismo histórico-dialético: encontros e desencontros na formação de educadores do campo. Revista Brasileira de Educação do Campo, v. 3, n. 3, p. 1009-1036, 7 dez. 2018. DOI:

https://doi.org/10.20873/uft.2525-4863.2018v3n3p1009.

PAITER, L. L. Reflexões sobre a formação docente na área de conhecimento ciências da natureza: a licenciatura em educação do campo. 2017. Dissertação (Mestrado) - Universidade Federal de Santa Catarina, Florianópolis, 2017. Disponível em: https://repositorio.ufsc.br/handle/123456789/186991. Acesso em: 10 fev. 2020.

PRSYBYCIEM, M. M.; SANTOS, A. P. DOS; SARTORI, J. Formação de professores em ciências da natureza para escolas do/no campo na UFFS - Campus Erechim: perspectivas e desafios. Revista Brasileira de Educação do Campo, v. 2, n. 3, p. 941964, 13 dez. 2017. Disponível em:

https://sistemas.uft.edu.br/periodicos/index.php/campo/article/view/3924. Acesso em: 8 mar. 2019.

SÁUL, T. S. Um olhar sobre a interdisciplinaridade nas licenciaturas em Educação do Campo nas Ciências da Natureza. 2018. Dissertação (Mestrado) - Universidade Federal de Santa Maria, Santa Maria, RS, 2018. Disponível em:

https://repositorio.ufsm.br/handle/1/16231. Acesso em: 12 mar. 2020.

SILVA, F. N. S.; LIMA, L. R. F. C.; MORADILLO, E. F.; MASSENA, E. P. Educação do campo e ensino de Ciências no Brasil: um estado do conhecimento dos últimos dez anos. Revista Brasileira de Ensino de Ciência e Tecnologia, v. 12, n. 1, p.221-239, 
jan./abr. 2019. Disponível em: https://periodicos.utfpr.edu.br/rbect/article/view/7547. Acesso em: 8 mar. 2019.

SILVA, D. K. A controvérsia agroecológica em uma abordagem intercultural de educação científica: a biodiversidade nos discursos de licenciandos do campo. Dissertação (Mestrado em Educação). Universidade Federal do Triângulo Mineiro, Uberaba, Minas Gerais, 2017a. Disponível em: http://bdtd.uftm.edu.br/handle/tede/978. Acesso em: 12 jan. 2020.

SILVA, M. C. L. Caminhos da interdisciplinaridade: da formação por área de conhecimento à prática educativa de egressos da Licenciatura em Educação do Campo PROCAMPO/IFPA/Campus de Castanha, PA. 2017b. Tese (Doutorado) - Universidade Federal do Ceará, Faculdade de Educação, Fortaleza, 2017.

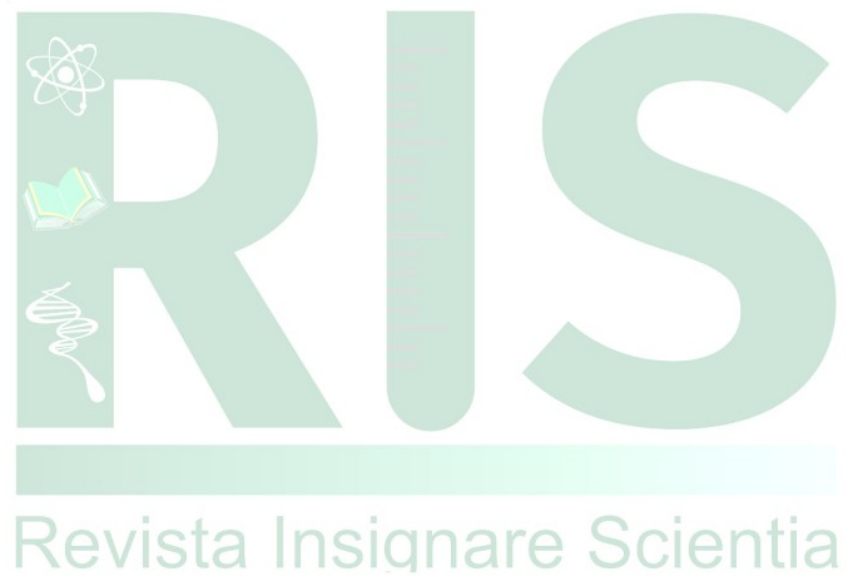

